\title{
Open Access Open Access Scientific Reports

\section{Bone Ingrowth to Insulin like Growth Factor-1 Loaded Zinc Doped Hydroxyapatite Implants: an In Vivo Study}

Brihat Chettri', Samit Kumar Nandi ${ }^{*}$, Abhijit Chanda² and Howa Begam ${ }^{2}$

${ }^{1}$ Department of Veterinary Surgery \& Radiology, West Bengal University of Animal and Fishery Sciences, Kolkata-700037, India

${ }^{2}$ School of Bioscience and Engineering, Jadavpur University, Kolkata-700032, India

\begin{abstract}
Hydroxyapatite (HAp) has been extensively used as bone substitutes of autologous and allogenic bone grafts and as coatings on metallic implants due to its good biocompatibility and bioactivity.

In order to increase bioactivity and osteoconductivity, HAp has been doped with zinc, a trace element available in bone. However, bone repairing capabilities have not been properly demonstrated after in vivo implantation with insulin like growth factor-1 (IGF-1) loaded zinc doped hydroxyapatite up to now. In this prospective, the concept of increased osteoinductivity was adopted to fabricate a combination product with zinc doped hydroxyapatite and insulin like growth factor- 1 toward the development of growth factor loaded construct. Porous hydroxyapatite alone and in combination with zinc dopants was characterized using XRD, FTIR, SEM, EDX and the mechanical property using Vickers hardness and fracture toughness for its physiochemical properties and subsequently applied in critical sized defect model in rabbit for a period of 3 months. Fluorochrome labeling, histological analysis, radiology and scanning electron microscopy (SEM) were performed to study angiogenesis, bone formation and osseous ingrowth. Interestingly, the histology of the IGF-1 loaded scaffold revealed well distribution of osteoblastic cell along with angiogenesis as compared to zinc doped and undoped HAp scaffold. Radiological, fluorochrome labeling and SEM observations demonstrated similar findings of more new bone formation, osseointegration and rapid mineralization indicating potentials for bone regeneration and repairing of bone defects.
\end{abstract}

Keywords: Hydroxyapatite; Zinc dopants; Insulin like growth factor-1; In vivo bone healing capability

Abbreviations: HAp - Hydroxyapatite; SEM- Scanning Electron Microscopy; IGF-1- Insulin like Growth Factor-1; ALP- Alkaline Phosphate; MPa- Mega Pascal; FTIR- Fourier Transform Infrared Spectroscopy; IM- Intra Muscular; mA - Milli Amperage; KV- Kilo Voltage

\section{Introduction}

Calcium phosphate ceramics have gained considerable dimension for several decades because the mineral phase of bone is calcium Hydroxyapatite (HAp) and instinctively integrate with living bone [1]. Excellent biocompatibility, minimal immunologic and systemic reaction made them ideal substitutes for autologous or allogenous bone grafts [2-5]. Apart from the presence of calcium and phosphate ions, bone contains several carbonate, magnesium, sodium and trace elements which took vital role in overall performance of bone. Nevertheless, further improvements on bioactivity, osteoconductivity and biodegradability are prerequisite which can significantly enhance faster bone growth and consequently promote the applications in orthopaedic surgery [6]. To achieve this goal, various researchers have tried to develop optimal calcium phosphate ceramics by improving processing techniques and rational compositional design [7-9].

Amongst the calcium phosphate ceramics, porous hydroxyapatite is the mostly applied materials in bone healing. Although there are several good qualities of synthetic HAp in bone healing, inherent brittleness makes them unsuitable in load bearing application [10]. To overcome these properties and to increase the bioactivity and osteoconductivity, several researchers have tried to find alternative ways and techniques to achieve appropriate biological and physiochemical properties in synthetic HAp for bone replacement. Addition of small amount of trace ions in HAp may have influence on the lattice parameters, the crystallinity, the dissolution kinetics [11] and possibly will have importance to improve mechanical properties and osseointegration.
Zinc is an essential trace element that plays vital role on osteoblastic cell proliferation and alkaline phosphate activity of bone cells in vivo and an inhibitory effect on osteoclastic bone resorption in vitro [1213]. Besides, $\mathrm{Zn}^{+2}$ at very low concentration has demonstrated to have a significant effect on increasing the growth of bone cells [12-13], enhanced osteoblast adhesion, alkaline phosphatase activity of bone cells [14-17], also decreased the inflammatory reaction [18] whereas higher concentrations of zinc into cell culture medium enhanced the ALP activity of osteoblast cells [19] but had deleterious effects on cell attachments and growth and even with $3.5 \mathrm{wt} . \% \mathrm{ZnO}$ doping caused cell death [20]. Thus the addition of zinc to hydroxyapatite may have important proposition for the proper integration to implant with bone. Further, bone repair is multifaceted biological phenomenon controlled by numerous cytokines and growth factors that ultimately help progenitors and inflammatory cells to migrate and enhance healing processes. Delivery of growth factors is one of the approaches to stimulate cellular adhesion, proliferation, and differentiation hence promoting bone regeneration [21]. The controlled delivery of growth factors can be done at localized orthopaedic sites through optimally designed biomaterial carriers as systemic administration of growth factors are often erratic, possibly due to their short biological half life, lack of long term stability, tissue specificity and potential dose dependent

*Corresponding author: Samit Kumar Nandi, Department of Veterinary Surgery \& Radiology, West Bengal University of Animal and Fishery Sciences, Kolkata-700037, India, Tel: +9133 9433111065; E-mail: samitnandi1967@gmail. com

Received May 14, 2012; Published August 10, 2012

Citation: Chettri B, Nandi SK, Chanda A, Begam H (2012) Bone Ingrowth to Insulin like Growth Factor-1 Loaded Zinc Doped Hydroxyapatite Implants: an In Vivo Study. 1: 234. doi:10.4172/scientificreports.234

Copyright: ( 92012 Chettri B, et al. This is an open-access article distributed unde the terms of the Creative Commons Attribution License, which permits unrestricted use, distribution, and reproduction in any medium, provided the original author and source are credited. 
carcinogenicity. Since hydroxyapatite has a micro pore structure and excellent biological property to the physiological condition, it can be used as slow release of the drug [22].

Based on all earlier results, it is necessary to understand new mechanisms how nontoxic and biocompatible zinc based hydroxyapatite materials alone and in combination with insulin like growth factor-1 would enhance more bone formation and better implant-bone integration in in vivo model. In fact there is no dearth of literature on the doped HAp, be it dense or porous, however, detailed clinical study of doped porous HAp, using in vivo study is yet to be reported. Moreover, the extent of betterment in the clinical performance of such doped HAP with the introduction of IGF-1 is also not reported in minute details. For this reason, the aim of the work is to present detailed study to determine the influence of $\mathrm{Zn}$ dopants alone and in combination with insulin like growth factor- 1 on osteoblast proliferation, osseointegration as well as its potential to promote mineralization at in vivo animal model onto porous hydroxyapatite scaffold. In the present work porous hydroxyapatite and zinc-doped hydroxyapatite were synthesized, characterized, loaded with osteoinductive protein i.e. insulin like growth factor-1 and consequently applied in critical sized bone defect in rabbit model.

\section{Material and Methods}

\section{Material characterization}

Powder synthesis: Pure hydroxyapatite powder was prepared using wet chemical method. In this method, G.R. grade calcium hydroxide $\left(\mathrm{Ca}(\mathrm{OH})_{2}\right)$ and orthophosphoric acid $\left(\mathrm{H}_{3} \mathrm{PO}_{4}\right)$ were used. $\mathrm{H}_{3} \mathrm{PO}_{4}$ solution was added drop by drop in the $\mathrm{Ca}(\mathrm{OH})$, solution in stirring condition. Synthesis was done at $80^{\circ} \mathrm{C}$ at a $\mathrm{pH}$ of $11-12$. The solution thus obtained was aged for $24 \mathrm{~h}$ and then filtered. After drying at $80^{\circ} \mathrm{C}$ the hydroxyapatite cake was sieved to get the powder for calcinations at $800^{\circ} \mathrm{C}$ for 2 hours. The calcined HAp powders were pressed at a pressure of $150 \mathrm{MPa}$ to get pellets in a uniaxial press. The pellets were then sintered at $1100^{\circ} \mathrm{C}$ for 1 hour to get porous structure. To get Porous Zn doped hydroxyapatite calcined HAp powder were ball milled with chitosan and $2 \% \mathrm{ZnO} 2$ for 4 hours for proper mixing. The $\mathrm{Zn}$ doped HAp powder was then pressed in uniaxial press at $150 \mathrm{MPa}$ and then sintered at $1200^{\circ} \mathrm{C}$ for 1 hour.

Characterization: $\mathrm{X}$-ray diffraction (XRD) technique was used to study the phase evolution and phase identification. Both the sintered samples Pure Hydroxyapatite (PPH) and Zinc Doped Hydroxyapatite $(\mathrm{PZH})$ were studied for phase identification in Rigaku diffractometer (Model-Miniflex, Rigaku Co., Tokyo, Japan) using $\mathrm{Kb}$ filtered $\mathrm{Cu} \mathrm{Ka}$ radiation in the step scanning mode with tube voltage of $30 \mathrm{KV}$ and tube current of $15 \mathrm{~mA}$. The XRD patterns were recorded in the $2 \theta$ range of $0-80^{\circ}$ with scan speed $1^{\circ}$ per min. Fourier Transform Infrared Spectroscopy (FTIR) was done to study the bonds present in the molecule. In our experiment, FTIR measurements were performed in mid IR region (5000-400 $\mathrm{cm}^{-1}$ ) using $\mathrm{KBr}$ pallets in a IR Prestige-21, Shimadzu instrument. The bulk density of the both sintered samples was calculated by simple gravimetric analysis. The morphology and the microstructure of the sintered samples were observed by scanning electron microscope. (SEM, S3000N, Hitachi, Japan). Elemental analysis was carried out by Energy Dispersive X-ray Spectroscopy (EDS) connected with SEM.

Hardness Test was carried out using a Vickers diamond indenter on an automated hardness tester (Model No-LV-700AT, LECO Co, MI). During the hardness test, a load of $0.3 \mathrm{Kgf}, 1 \mathrm{Kgf}$ and $3 \mathrm{Kgf}$ was applied on both PPH PZH samples for their hardness at three different locations with three different loads. The average of these readings were computed, reported and compared.

Fracture Toughness (K1c) was calculated using simple equation considering radial-median crack geometry: $\mathrm{K}_{1 \mathrm{c}}=0.016(\mathrm{E} / \mathrm{H})^{1 / 2} \mathrm{P} /(\mathrm{c})^{3 / 2}$

We measured the average crack length which was developed by indentation at the time of hardness testing. We measured the crack length and confirmed that the ratio of crack length to half the diagonal exceeds 2.5 , the prerequisite for assuming radial median crack geometry.

\section{Implant loading with IGF-1}

Recombinant human IGF-I, $30 \mu \mathrm{g} /$ implant (Enzo Life Sciences, Switzerland) was dissolved in $0.1 \%$ sterile bovine serum albumin in PBS. IGF-I was adsorbed onto the surfaces of the interconnecting porous zinc doped hydroxyapatite implants at $4^{\circ} \mathrm{C}$ in sterile conditions under vacuum.

\section{In vivo study}

The animal experimentation has been carried out following the standards conforming to the Institutional Animal Ethics Committee of West Bengal University of Animal and fishery sciences, India. A total of sixteen (16) New Zealand rabbits of either sex, 2-2.5 kg. body weight were randomly distributed into 4 groups of 4 animals each, as follows: 1) control (Gr. 1), in which the bone defect was not treated, 2) test specimens (Gr. 2), in which hydroxyapatite scaffold alone, 3) test specimens in which zinc doped hydroxyapatite scaffold (Gr. 3) and 4) test specimens (Gr. 4), in which hydroxyapatite with IGF1. Under aseptic measures, critical sized defect $\left(0.8 \times 0.4 \times 0.3 \mathrm{~cm}^{3}\right)$ in proximal tibia was created in each animal by micro motor dental drill with sterile cold normal saline irrigation after exposing the bone and under sedation with xylazine hydrochloride (XYLAXIN ${ }^{\bullet} 1 \mathrm{mg} / \mathrm{kg}$ body weight; Indian Immunologicals, India) and Ketamine hydrochloride (KETALAR $^{\oplus}$, Parke-Davis, India) in combination with local $2 \%$ lignocaine hydrochloride (XYLOCAINE ${ }^{\oplus}$, Neon Laboratories, India). The implants were press fitted in position and kept secure by suturing the muscle, subcutaneous tissue, and skin in layers. Postoperatively, all the animals received cefotaxime sodium (125 mg IM twice daily; Mapra India, India) and injectable meloxicam (MELONEX ${ }^{\oplus}, 0.2 \mathrm{~mL}$ once daily for 5 days; Intas Pharmaceuticals, India) with daily dressing changes of the surgical wounds.

Sequential radiographs were taken at regular, calculated intervals on days $0,30,60$ and 90 to outline bone-material interface and estimate the extent of bonding. This was further verified by detailed SEM study at the end of study of 90 days. To obtain electro-magnetic signals the samples were golden ion sputtered on Jeol ion sputter Model JFC 1100 at 7 to $10 \mathrm{~mA}$ and $1-2 \mathrm{KV}$ for 5 minutes. Finally, they were examined in scanning electron microscope (Jeol JSM 5200 model) for observing different surfaces to understand the orientation and distribution of newly formed osseous tissues within the materials at the defect site and finally compared among all scaffolds together with control. After sacrifice, the proximal tibias were harvested for histological analysis to check the cellular response of host bone to the implants. Bone specimens from adjacent bone at the side and at the bottom of the original bone defect were collected and washed thoroughly with normal saline and were fixed in 10\% formalin for 7 days. All specimens of bone tissue were decalcified (Goodling and Stewart's fluid containing formic acid $15 \mathrm{~mL}$, formalin $5 \mathrm{~mL}$ and distilled water $80 \mathrm{~mL}$ solution), followed by fixation with $4 \%$ para-formaldehyde. The samples were then embedded into paraffin wax, $4 \mu \mathrm{m}$ sections were prepared and stained 
Citation: Chettri B, Nandi SK, Chanda A, Begam H (2012) Bone Ingrowth to Insulin like Growth Factor-1 Loaded Zinc Doped Hydroxyapatite Implants: an In Vivo Study. 1: 234. doi:10.4172/scientificreports.234

Page 3 of 9

with haematoxyline and eosin. Finally, fluorochrome (oxytetracycline dehydrate; Pfizer India, India), at a dose of $50 \mathrm{mg} / \mathrm{kg}$ body weight, was given on days 77,78 and 85,86 (2-6-2 manner) post-operatively for double-toning of new bone. Undecalcified ground sections were prepared from the implanted segments of bone and the sections were ground to $20 \mu \mathrm{m}$ thickness using different grades of sand paper. The ground undecalcified sections were observed under ultraviolet incidental light with an Orthoplan microscope (Excitation filter, BP400 range, Leitz, USA) to analyze bone formation within the implants.

\section{Results}

\section{Material characterization}

Figure 1(a) and (b) shows the XRD pattern of pure hydroxyapatite $(\mathrm{PPH})$ and zinc doped hydroxyapatite $(\mathrm{PZH})$ respectively. Major peaks were found at 31.7 according to PDF 09-432 for both samples. In the zinc doped HAp the crystallite was phase pure and the zinc doping did not alter the phase of the hydroxyapatite.

The obtained FTIR pattern of pure Hap and zinc doped HAp was presented in Figure 2. In Figure 2(a) the intense peak at 3570 reveals the presence of hydroxyl group. As shown in Figure 2(a), zinc doped HAp showed two peaks at 3419 and 3550 which signifies the presence of hydroxyl group. The peaks at 1074 in PPH and peaks at 1007 in $\mathrm{PZH}$ reveal the presence of $\mathrm{PO}_{4}$ groups.
The bulk density of both samples PPH and PZH were calculated by measuring the mass and volume. We got density $2.17 \mathrm{gm} / \mathrm{CC}(68.68 \%)$ and $31.33 \%$ porosity for pure HAp. For the Zinc doped HAp the bulk density was $1.73 \mathrm{gm} / \mathrm{CC}$ with $45.02 \%$ porosity.

The scanning electron microscopy was carried out for the both sample $\mathrm{PPH}$ and $\mathrm{PZH}$ to study the surface morphology and the microstructure. The grain size for $\mathrm{PPH}$ ranges from 0.247 micron to 0.544 micron and for PZH grain size ranges from 0.698 micron to 1.397 micron. It was observed that the gains were spherical shaped for both samples as shown in Figure 3(a) and (b). Pores were observed in the SEM micrograph and the pores were interconnected. The EDX study showed the presence of $\mathrm{Ca}, \mathrm{P}$ and $\mathrm{O}$ in $\mathrm{PPH}$ sample and $\mathrm{Ca}, \mathrm{P}, \mathrm{O}$ and $\mathrm{Zn}$ in PZH sample Figure 4(a) and (b).

The Vickers hardness measurement was conducted in three different loads in three different locations on the samples. We applied $0.3 \mathrm{Kgf}, 1 \mathrm{Kgf}$ and $3 \mathrm{Kgf}$ and then we calculated the average value of hardness. We also calculated the average value of fracture toughness for $\mathrm{PPH}$ samples. The values of hardness are listed in the table given below:

We could not calculate the average crack length of $\mathrm{Zn}$ doped HAp because the crack propagation was not found clearly from the site of indentation. Most of the cracks merged with the inherent pores that
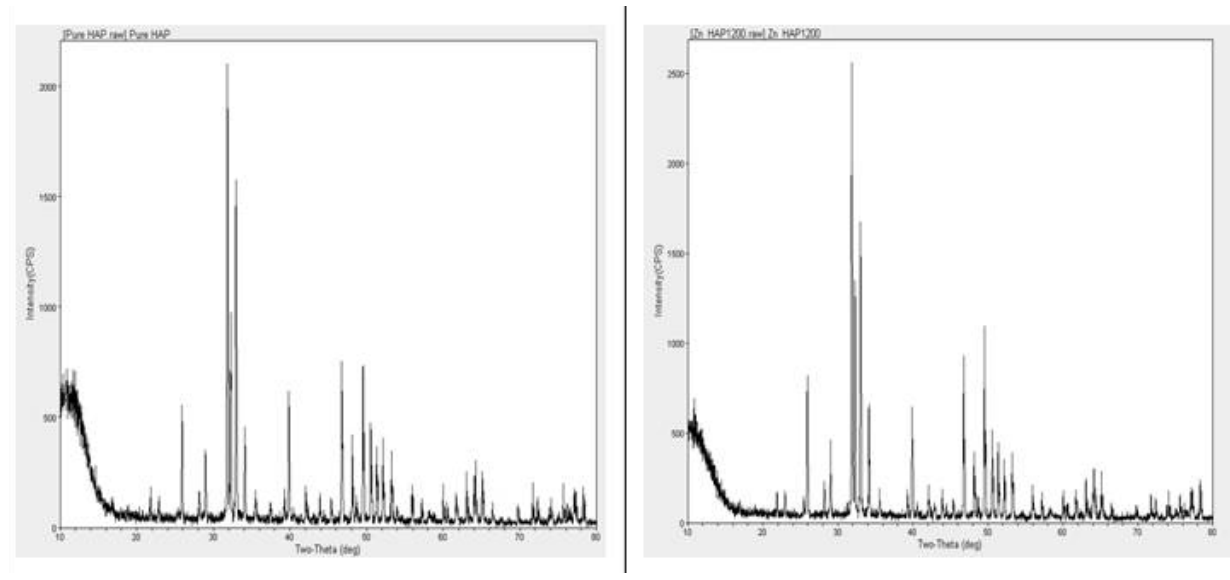

Figure 1: XRD pattern of (a) porous pure HAp (PPH) and Porous $\mathrm{Zn}$ doped HAp (PZH).
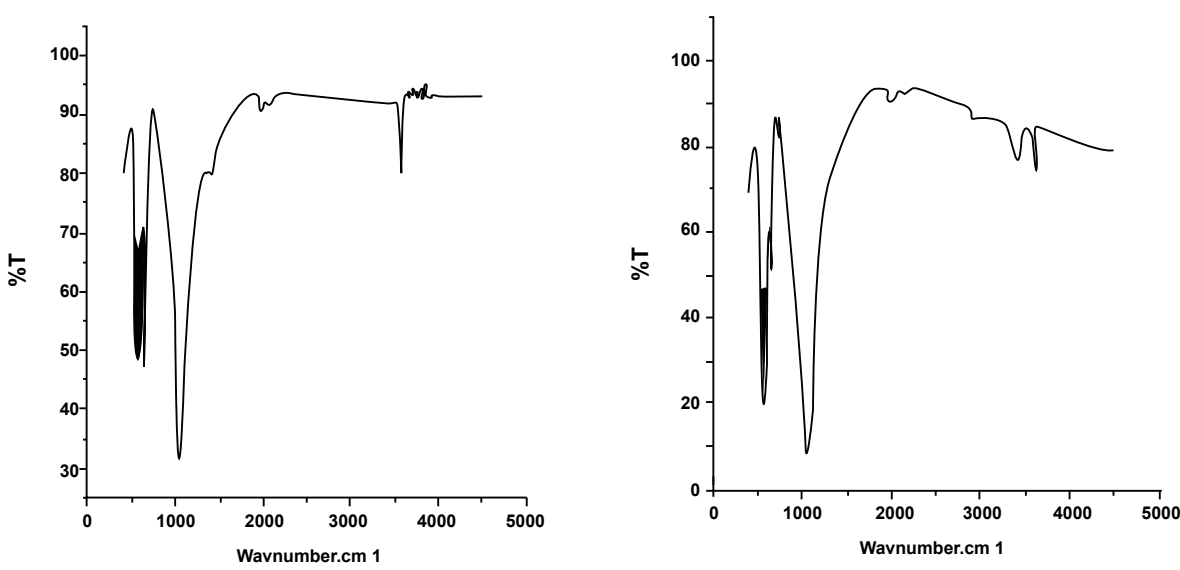

Figure 2: FTIR spectra of (a) porous pure HAp (PPH) and Porous Zn doped HAp (PZH). 


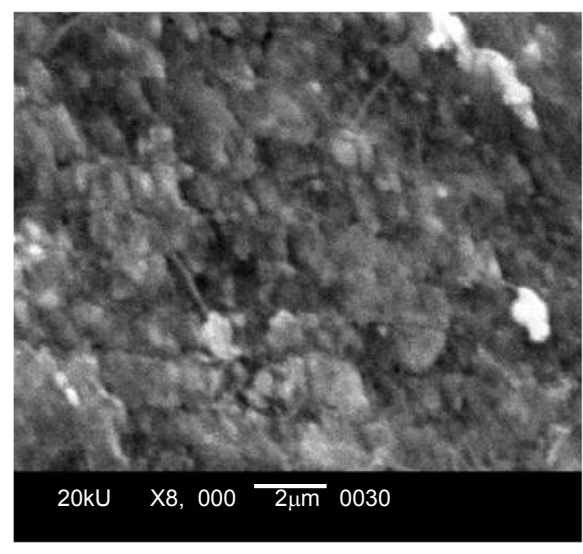

(a)

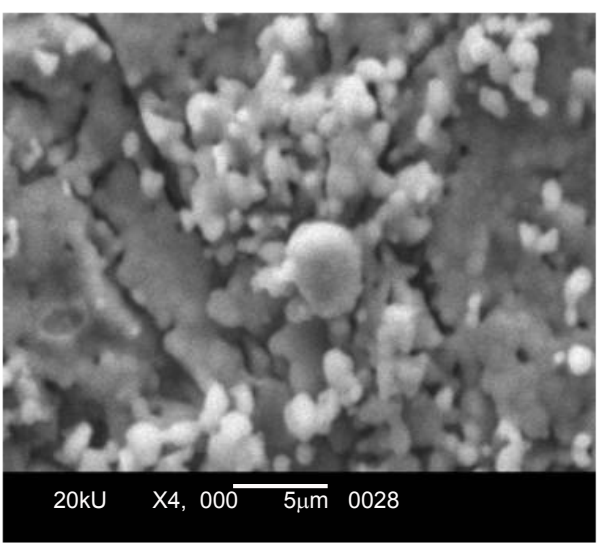

(b)

Figure 3: SEM Micrograph of (a) porous pure HAp (PPH) and Porous Zn doped HAp (PZH).

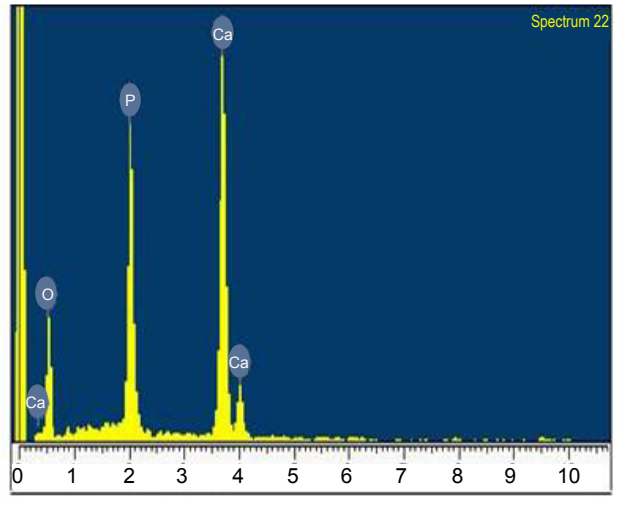

(a)

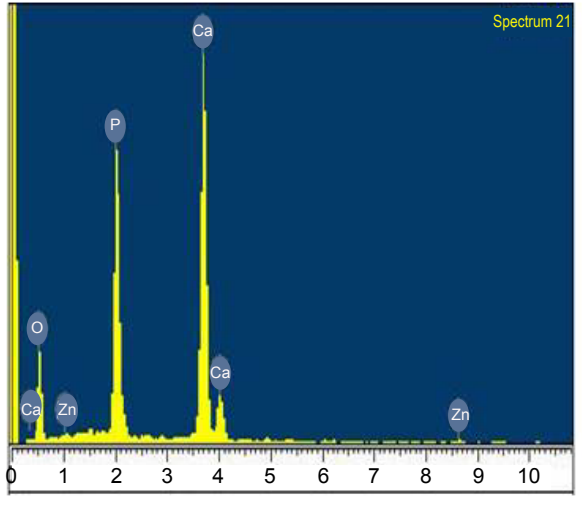

(b)

Figure 4: EDX plot of (a) porous pure HAp (PPH) and Porous Zn doped HAp (PZH).

made measurement difficult. In none of the cases, crack length could be measured to calculate the fracture toughness for the samples.

\section{In vivo Study}

Radiological observations: A tibial defect model was employed to evaluate the bone healing and regeneration. As shown in Figure 5a, defect hole was observed in proximal tibia as evidenced by radiolucent zone at 0 day. The radiolucent zone was still present on day 30 except substantial reduction of gap along with periosteal reaction in the surrounding area. The shadow of radiolucency still existed on day 60 and 90 except the gap is reduced by osseous tissue. As shown in Figure $5 \mathrm{~b}$, proximal part of tibia showed presence of well placed radiodense material at 0 day. The radiograph on day 30 showed presence of material with interfacial gap between bone and implant and rounding of all corners of defect. On day 60 and 90, the material still existed with gradual reduction of interfacial gap indicating formation of bone ingrowth. As shown in Figure 5c, radiograph demonstrated well placed radiodense material in proximal tibia on day 0 and showed gradual reduction of radiolucency between bone and implant at day 30 . On day 60 and 90, although radiodense material was still present, the radiolucency between bone and implant is substantially reduced and more bone formation within the implanted area. As shown in Figure 5d, the radiodense material was present through the experimental period but the radiolucent gap between bone and implant almost disappeared on day 60 and 90 . The radiodensity of implant approached normalcy to the host bone on day 90 indicating rapid bone ingrowth, conjugation with host bone and mineralization.

Microstructural study (SEM): Figure 6 (a-c) shows microstructural study carried out by scanning electron microscopy at 3 months postsurgery. As shown in Figure 6a, there was substantial interfacial gap between the bone and implant with some osseous ingrowth over the implant in HAp implanted bone. In zinc doped HAp implanted bone showed nearly completing interfacial zone with the presence of biological material in the gap and better tissue on-growth over the implant (Figure 6b). As shown in Figure $6 \mathrm{c}$, the interfacial gap between the bone and implant was almost absent with the presence of substantial tissue on-growth over the implant.

Histological observations: Figure $7(\mathrm{a}-\mathrm{d})$ shows Hematoxylin and Eosin (HE) staining images at 3 months post-surgery, exhibiting the cellular responses between the implants and the host bone tissues after implantation of porous HAp, zinc doped porous HAp and IGF1 loaded zinc doped HAP and compared with control. As shown in Figure $7 \mathrm{a}$, moderately developed bony osteoid with few angiogenic 
Gr. 1

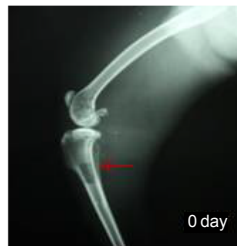

Gr. 2

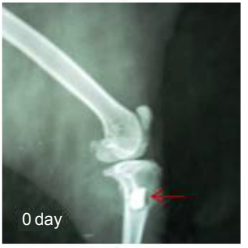

Gr. 3

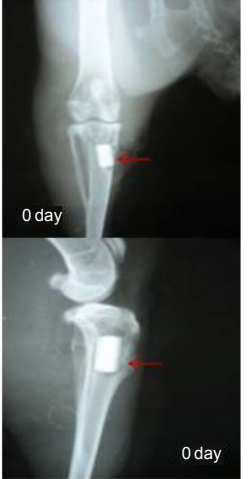

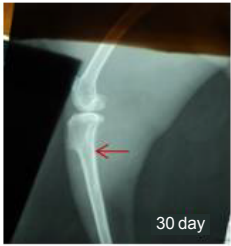
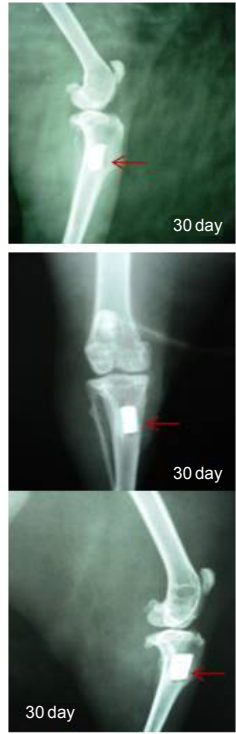
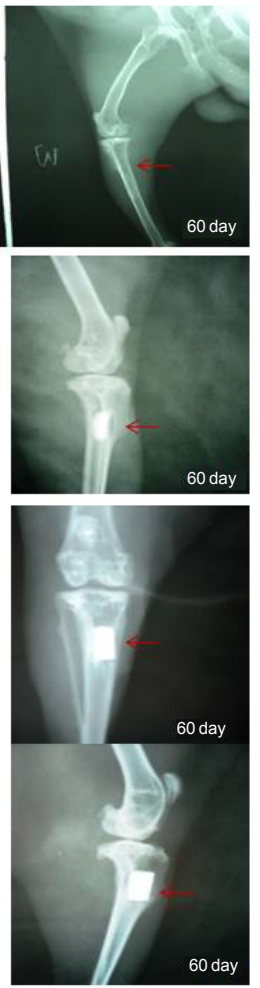
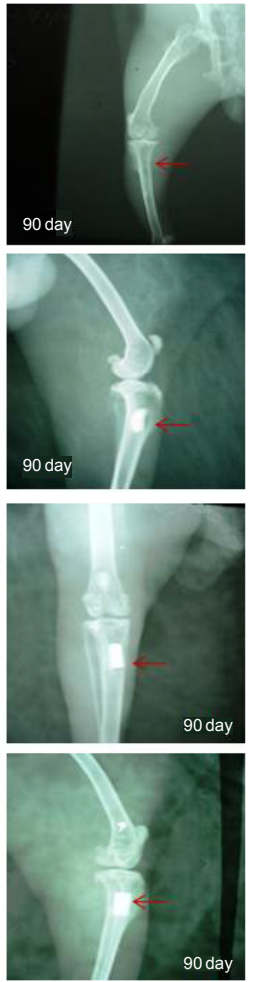

Figure 5 (A-B): Serial radiographs at different days of interval in different groups upto 90 day post-operatively.

points and presence of RBC and mononuclear cells were observed in control bone samples. Figure $7 \mathrm{~b}$ in porous hydroxyapatite bone showed canalized haversian system with lamellar deposition of fibrocartilaginous tissue, osteoblast and few vascular points. Figure $7 \mathrm{c}$ in zinc doped hydroxyapatite bone showed well developed haversian canal with proliferative lamellar mass with angiogenic points whereas IGF-1 loaded doped hydroxyapatite exhibited well developed haversian canal and osseous canaliculi inssipited by fairly developed calcareous mass and proliferating osteoblast along with angiogenesis (Figure 7d).

Fluorochrome labeling observations: Figure 8(a-d) shows fluorochrome labeling images at 3 months post-surgery, exhibiting new bone formation as evidenced by golden yellow fluorescence where as sea green colour appears host bone. As shown in Figure 8a, the activity of new bone formation in control bone was very less, as evidenced by narrow zone of golden yellow fluorescence and mostly old bone appearance was observed where as in HAp placed bone showed substantial increase of new bone formation in the defect area as compared to control bone (Figure $8 \mathrm{~b}$ ). As shown in Figure $8 \mathrm{c}$ in zinc doped hydroxyapatite, intensity of new bone formation was moderate as evidenced by better zone of golden yellow fluorescence in endosteal area of bone defect while the periosteal area showed mostly light sea green appearance. In IGF-1 loaded doped HAp bone showed marked golden yellow fluorescence of newly formed bone originated both from endosteal and periosteal surface showing good osseous activity (Figure $8 \mathrm{~d})$.

\section{Discussion}

Wide spread biological and biomechanical research has been conducted for treatment of bone defects [23-24]. Even though the majority of fractures do heal well, the treatment of large skeletal defects has a primary concern to the orthopedic surgeons and poses challenges in curing such disorders. Autogenous bone grafts are still considered as gold standard in revision surgery [25] but several drawbacks limited their use in clinical situation.

As a result, research through biological and mechanical approaches gained considerable dimension toward improving bone tissue defect healing [26]. The significant biocompatibility and osteoconductivity of calcium phosphate bioceramics especially hydroxyapatite have led to its widespread use in bone reconstructive surgery [26-30]. Hydroxyapatite with highly interconnected porosity is better than dense HA as an alternative to bone grafts [31] as porous structure enables osseous ingrowth into the implant which supports mechanically stable and biologically integrated repair.

An active bone hydroxyapatite interface is one of the most prerequisites in osseointegration process for the close bonding of ceramic materials to living tissue [32]. This is achieved through processes of dissolution and precipitation of carbonate apatite associated with bone leading to a strong material-bone interface [3233]. In addition to calcium and phosphate ions, bone contains some trace elements like carbonate, magnesium, sodium etc. which may play distinct role in overall performance of bone [28,34]. Addition of small amount of dopants and more importantly, zinc may trigger the osteoconductivity of the porous hydroxyapatite implant. Zinc addition in calcium phosphate can control grain growth and increase density, has stimulatory effects on bone formation [35] and has shown to inhibit osteoclastic bone resorption [36].

Apart from the activity of dopants, current approaches for bone tissue regeneration have been centered on rapid cell growth and high cell differentiation in implantable matrices that mimic biological tissues 
Citation: Chettri B, Nandi SK, Chanda A, Begam H (2012) Bone Ingrowth to Insulin like Growth Factor-1 Loaded Zinc Doped Hydroxyapatite Implants: an In Vivo Study. 1: 234. doi:10.4172/scientificreports.234
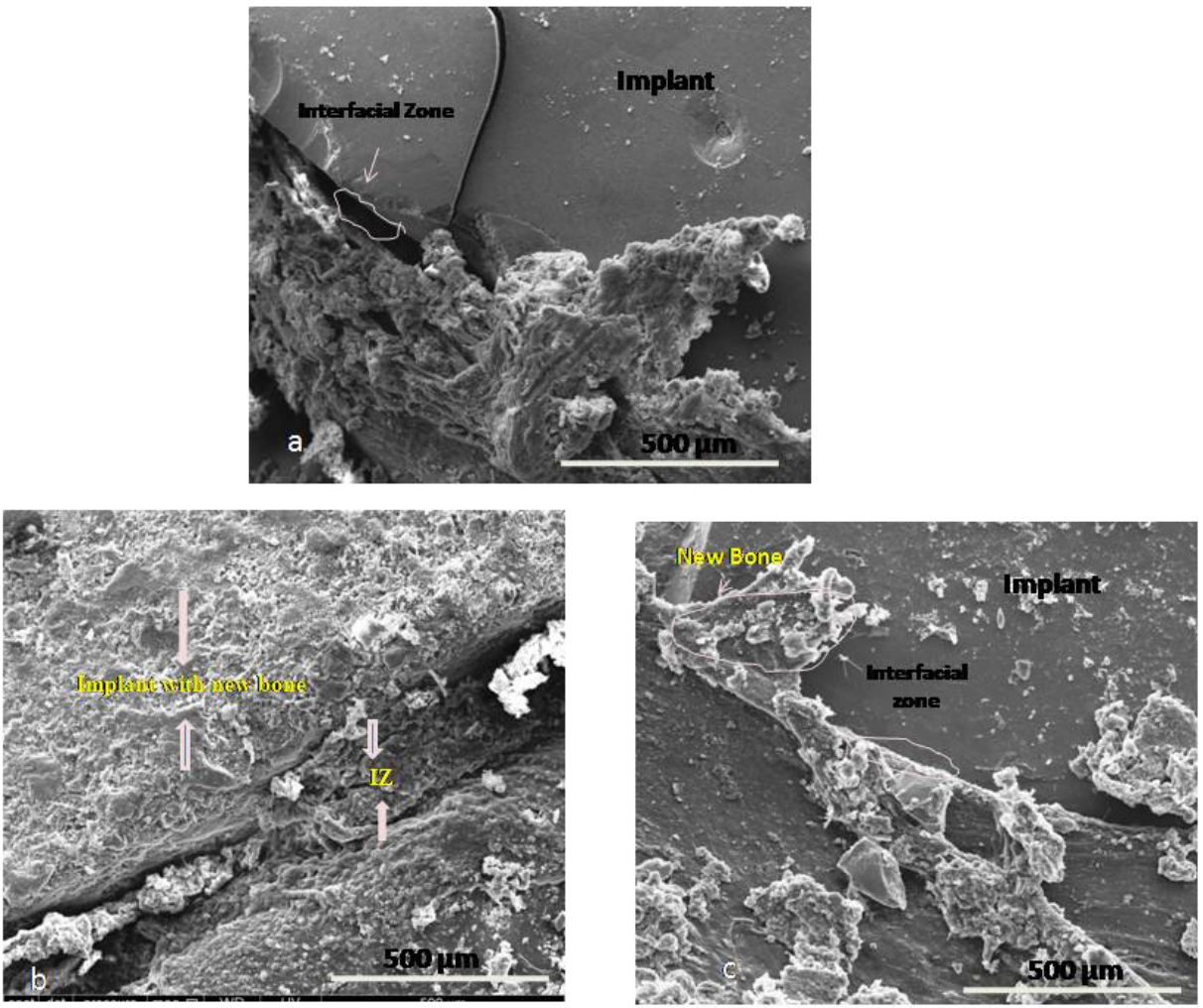

Figure 6 (A-C): Scanning electron microscopy of implanted bone at 90 day post-operatively (NB- New bone, IZ- Interfacial zone, a- HAp implanted bone; b-Zinc doped HAp implanted bone; c- Zinc doped HAp with IGF-1 implanted bone).
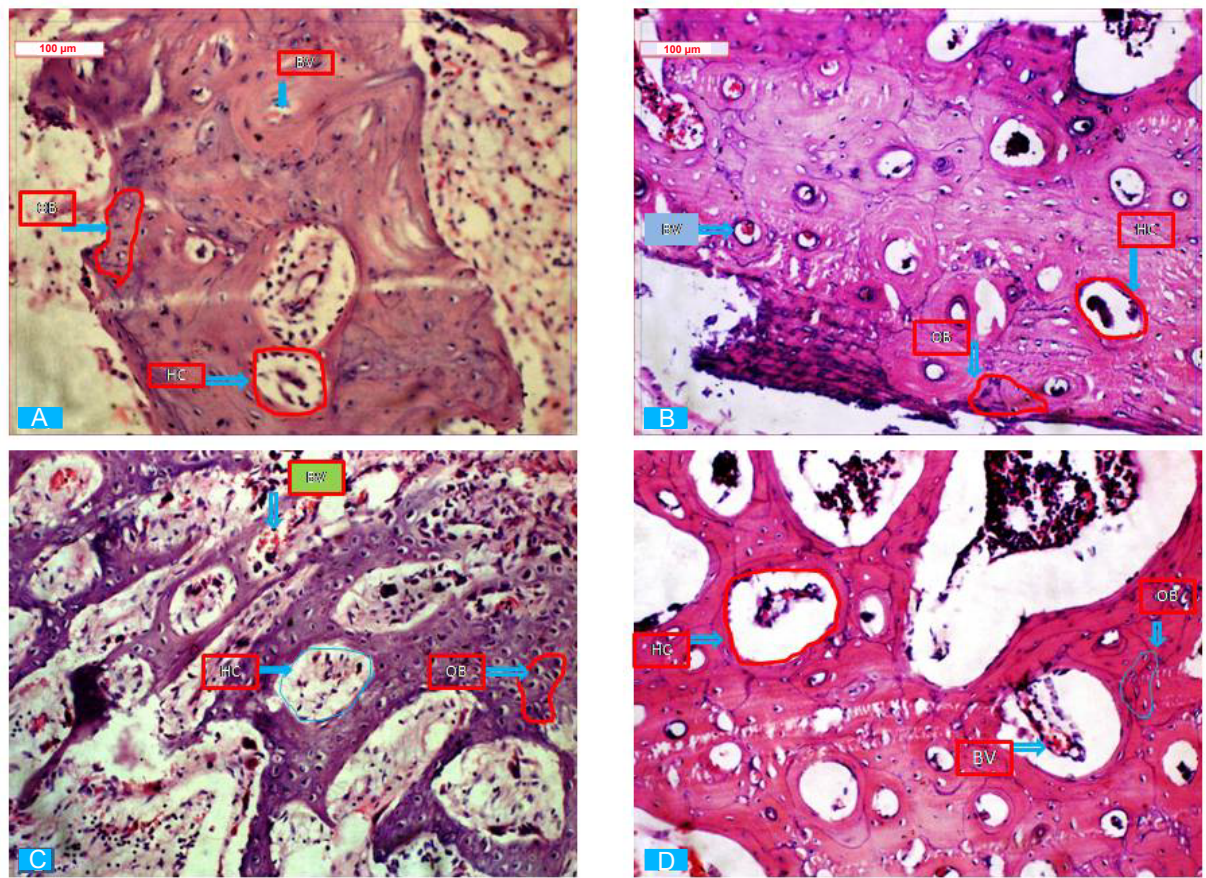

Figure 7 (A-D): Hematoxylin and Eosin (HE) staining histological images at 3 months post-operatively (A- Gr. 1, B-Gr. 2, C-Gr. 3, D- Gr. 4; OB- Osteoblast, BVBlood vessel, HC- Haversian canal).

[37]. Amongst the various approaches, growth factor delivery through a porous scaffold into the localized site can improve the biological properties of porous scaffolds either by inducing osteogenesis or vascularization [38-42]. IGF-1 is one such growth factor which can 
Citation: Chettri B, Nandi SK, Chanda A, Begam H (2012) Bone Ingrowth to Insulin like Growth Factor-1 Loaded Zinc Doped Hydroxyapatite Implants: an In Vivo Study. 1: 234. doi:10.4172/scientificreports.234

Page 7 of 9
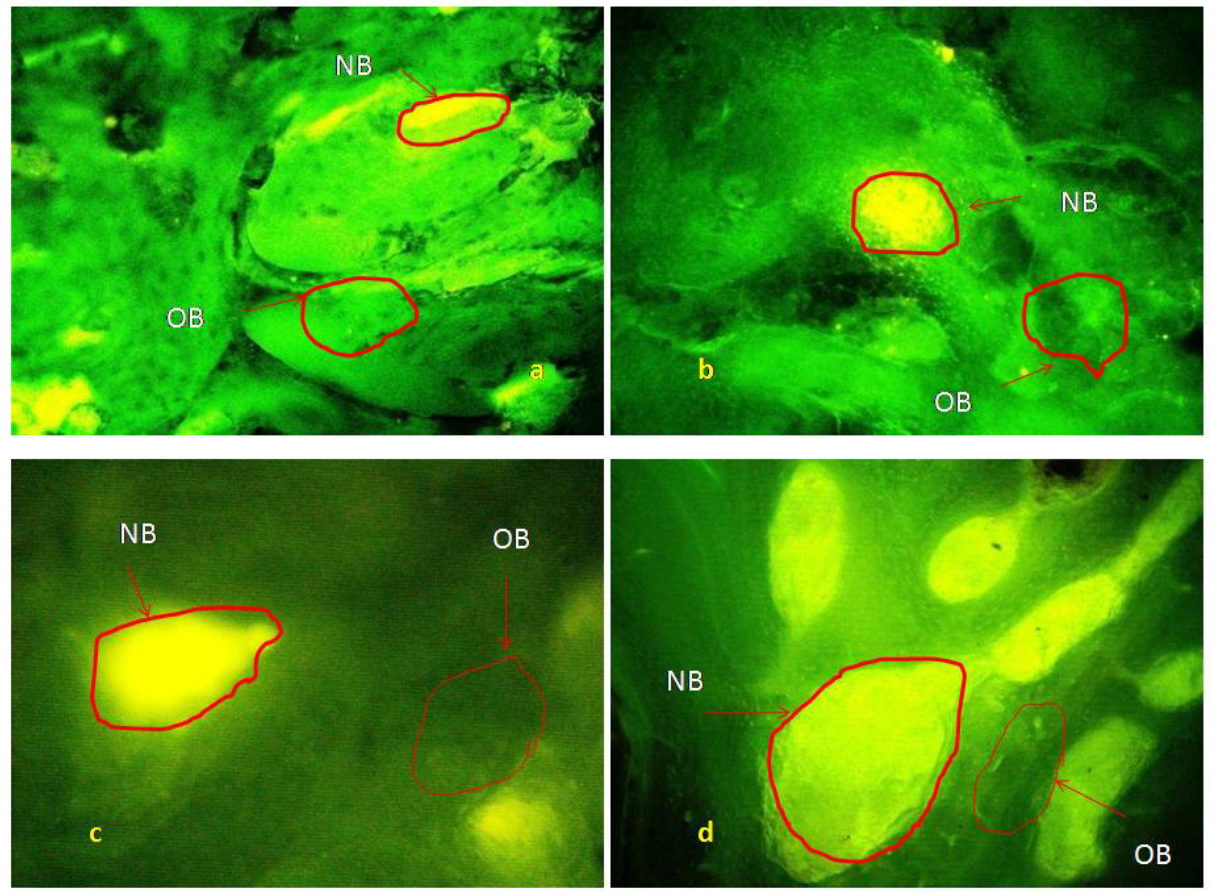

Figure 8: Fluorochrome labeling images at 3 months post-operatively (a- Gr. 1, b- Gr. 2, c- Gr. 3, d- Gr. 4; NB- New bone, OB- Old bone).

stimulate osteoblast proliferation and bone matrix synthesis [43]. The aim of the present study was to explore the biological activity of a synthetic zinc doped porous hydroxyapatite made in our laboratories and to observe whether IGF-I, a mitogen of primary osteoblasts [44] can stimulate new bone ingrowth when loaded onto doped implants.

Radiography is an excellent tool in assessing the union at the host bone-implant interfaces during the follow-up of implanted biomaterials [45]. A distinct radiolucent zone at the interface between implants and the host bone is generally seen on the immediate postoperative radiographs. The gradual absence of this radiolucent zone is considered to be an indication of union between the implant and the host bone [46-47]. In the present study, sequential radiographs from the animals of all groups are taken and the results are summarized in Figure 5. With time, the reduction of radiolucent gap between bone and implant confirms the good bonding vis-à-vis faster bone repairing and remodeling process in IGF-1 loaded zinc doped HAp implanted bone where as zinc doped HAp scaffold bone showed substantial reduction of radiolucent gap suggesting progressive bone healing within the defect area. This may due to the effects of zinc dopants and similar type of results have been observed using zinc dopants [48]. In porous HAp implanted bones, gradual reduction of interfacial gap is shown indicating initiation of bone ingrowth within this time where as little bone ingrowth is evidenced in control, sham bone. The bone defect can be seen clearly and kept their original shapes pretty nearly except the reduction of defect gap.

To further understand the mechanisms of bone remodeling, histological and SEM studies have been carried out in the present study. As indicated in the histological and SEM analysis, higher osseointegration capability was detected for IGF-1 loaded doped porous HAP and only doped HAp as compared to HAp and control bone. At 90 days post implantation, well developed haversian canal and osseous canaliculi along with proliferating osteoblast and angiogenesis are detected in Gr.4. Whereas well developed haversian canal with proliferative lamellar mass with angiogenic points are observed in Gr. 3. Microstructural studies through SEM also demonstrates similar findings with enhanced integration at the bone-implant interface, nearly no presence of gap and almost complete integration of bony and soft tissue into the porous structure in Gr. 4 as compared to Gr. 3 . The osteoid formation along the transplanted material is clearly visible, confirming proliferation of more osteoblastic cells and subsequent bone matrix deposition [49]. The enhanced and interconnected porosity of the doped hydroxyapatite implant allows osteoprogenitor cell penetration, cell migration, and attachment enabling new bone ingrowth and thus forming a strong bond with the periprosthetic bone [43]. The presence of porosity, predominantly interconnected porosity, offers higher surface area for improved mechanical interlocking between the scaffolds and surrounding host tissue [50-51] and also provides pathways for micronutrients [52]. Moreover, in the present study, addition of IGF-1, known to stimulate osteoblast proliferation $[44,53]$, has been used to improve the bioactivity of doped HAp implant to yield better repair of a bony defect. In addition, IGF-I plays definite role with increased type I collagen transcription, bone matrix apposition and inhibition of bone collagen degradation [54]. In contrast, only HAp and control bone show moderately developed canalized haversian system with lamellar deposition of fibro-cartilaginous tissue, osteoblast and few vascular points which may be due to the lack of sufficient osteoblastic cell population within the implant center.

Fluorochrome labeling studies by tetracycline marker are also conducted in the present study to understand the difference in new bone formation in the implanted bone defect of all groups. Tetracycline is generally absorbed to the areas where active deposition of mineralized tissue is taking place [55-56]. The labeled new bone and old bone discharge bright golden-yellow and dark, sea green fluorescence respectively when observed under UV light and this offers practical information in assessing the amount of new bone formation and bone 
Citation: Chettri B, Nandi SK, Chanda A, Begam H (2012) Bone Ingrowth to Insulin like Growth Factor-1 Loaded Zinc Doped Hydroxyapatite Implants: an In Vivo Study. 1: 234. doi:10.4172/scientificreports.234

healing $[46-47,57]$.The IGF-treated doped samples show an increased amount of primary bone ingrowth into the area as evidenced by more golden yellow fluorescence than doped HAp, HAp and control bone respectively. The increase amount of new bone deposition was brought about by an increase in mineral apposition rate which may be due to the combining stimulatory effects of zinc dopants and IGF-1 in HAp implants. .

\section{Conclusions}

The results of the present study suggest that addition of zinc dopants alone and in combination with insulin like growth factor-1 would be effective in further enhancing the osteoconductivity and osteoinductivity of porous hydroxyapatite scaffold by supporting rapid new bone formation in osseous defects. The results also suggest that zinc doped porous HAp implants might provide a delivery system for bioactive agents to accelerate bone healing and better anchorage of bone implants in orthopedic surgery. However, further detailed studies are needed to elucidate the exact mechanisms of zinc dopants on enhanced bone healing for suitable use in future biomedical applications as a more osteoconductive bone substitute.

\section{Acknowledgements}

The authors sincerely acknowledge the help and facilities provided by the Dean, Faculty of Veterinary and Animal Sciences, West Bengal University of Animal and Fishery Sciences, Kolkata, India for the research work. The authors also acknowledge the help rendered by the staff members of School of Bio Science \& Engineering, Jadavpur University, Kolkata, India.

\section{References}

1. Hench LL, Wilson J (1993) An Introduction to bioceramics. (1stedn), World Scientific, Singapore

2. Hing KA, Saeed S, Annaz B, Buckland T, Revell PA (2004) Microporosity affects bioactivity of macroporous hydroxyapatite bone graft substitutes. Key Engineering Materials 254-256: 273-276.

3. Burg KJ, Porter S, Kellam JF (2000) Biomaterial developments for bone tissue engineering. Biomaterials 21: 2347-2359.

4. Itoh S, Kikuchi M, Koyama Y, Takakuda K, Shinomiya K, et al. (2002) Development of an artificial vertebral body using a novel biomaterial, hydroxyapatite/collagen composite. Biomaterials 23: 3919-3926.

5. Du C, Cui FZ, Zhang W, Feng QL, Zhu XD, et al. (2000) Formation of calcium phosphate/collagen composites through mineralization of collagen matrix. J Biomed Mater Res 50: 518-527.

6. Ducheyne P, Qiu Q (1999) Bioactive ceramics: the effect of surface reactivity on bone formation and bone cell function. Biomaterials 20: 2287-2303.

7. Cai S, Zhang WJ, Xu GH, Li JY, Wang DM, et al. (2009) Microstructural characteristics and crystallization of $\mathrm{CaO}-\mathrm{P} 2 \mathrm{O} 5-\mathrm{Na} 2 \mathrm{O}-\mathrm{ZnO}$ glass ceramics prepared by sol-gel method. J Non Cryst Solids 355: 273-279.

8. Fellah BH, Layrolle $P$ (2009) Sol-gel synthesis and characterization of macroporous calcium phosphate bioceramics containing microporosity. Acta Biomater 5: 735-742.

9. Murphy S, Boyd D, Moane S, Bennett M (2009) The effect of composition on ion release from Ca-Sr-Na-Zn-Si glass bone grafts. J Mater Sci Mater Med 20: 2207-2214.

10. Rose FR, Oreffo ROC (2002) Bone tissue engineering: Hope vs. hype. Biochem Biophys Res Commun 292: 1-7.

11. Miao S, Weng W, Cheng K, Du P, Shen G, et al. (2005) Sol-gel preparation of $\mathrm{Zn}$-doped fluoridated hydroxyapatite films. Surf Coat Technol 198: 223-226.

12. Yamaguchi M, Oishi H, Suketa $Y$ (1987) Stimulatory effect of zinc on bone formation in tissue culture. Biochem Pharmacol 36: 4007-4012.

13. Moonga BS, Dempster DW (1995) Zinc is a potent inhibitor of osteoclastic bone resorption in vitro. J Bone Miner Res 10: 453-457.

14. Ito A, Ojima K, Naito H, Ichinose N, Tateishi T (2000) Preparation, solubility, and cytocompatibility of zinc-releasing calcium phosphate ceramics. J Biomed Mater Res 50: 178-183.

15. Ito A, Kawamura H, Otsuka M, Ikeuchi M, Ohgushi H, et al. (2002) Zincreleasing calcium phosphate for stimulating bone formation. Mater Sci Eng: C 22: $21-25$

16. Webster TJ, Massa-Schlueter EA, Smith JL, Slamovich EB (2004) Osteoblas response to hydroxyapatite doped with divalent and trivalent cations. Biomaterials 25: 2111-2121.

17. Sogo Y, Ito A, Kamo M, Sakurai T, Onuma K, et al. (2004) Hydrolysis and cytocompatibility of zinc-containing a-tricalcium phosphate powder. Mater Sci Eng: C 24: 709-715.

18. Grandjean-Laquerriere A, Laquerriere P, Jallot E, Nedelec J-M, Guenounou $M$, et al. (2006) Influence of the zinc concentration of sol-gel derived zinc substituted hydroxyapatite on cytokine production by human monocytes in vitro. Biomaterials 27: 3195-3200

19. Hall SL, Dimai HP, Farley JR (1999) Effects of zinc on human skeletal alkaline phosphatase activity in vitro. Calcif Tissue Int 64: 163-172.

20. Bandyopadhyay A, Withey EA, Moore J, Bose S (2007) Influence of ZnO doping in calcium phosphate ceramics. Mater Sci Eng: C 27: 14-17.

21. Schnettler R, Knöss PD, Heiss C, Stahl JP, Meyer C, et al. (2008) Enhancement of bone formation in hydroxyapatite implants by rhBMP-2 coating. J Biomed Mater Res B: Appl Biomat 90: 75-81.

22. Lima IR de, Costa AM, Bastos IN, Granjeiro JM, Soares G de (2006) Development and characterization of $5 \% \mathrm{~mol} \mathrm{Zn}$ bioceramic in granular form. Materials Research 9: 399-403.

23. Hench LL (1988) Bioactive ceramics. Ann N Y Acad Sci 523: 54-71.

24. Hench LL (1989) Bioceramics and the origin of life. J Biomed Mater Res 23 685-703.

25. Yaszemski MJ, Payne RG, Hayes WC, Langer R, Mikos AG (1996) Evolution of bone transplantation: molecular, cellular and tissue strategies to engineer human bone. Biomaterials 17: 175-185.

26. Eggli PS, Müller W, Schenk RK (1988) Porous hydroxyapatite and tricalcium phosphate cylinders with two different pore size ranges implanted in the cancellous bone of rabbits. A comparative histomorphometric and histologic study of bony ingrowth and implant substitution. Clin Orthop Relat Res 232 : 127-138.

27. Dorozhkin SV (2010) Bioceramics of calcium orthophosphates. Biomaterials 31:1465-1485

28. Bandyopadhyay A, Bernard S, Xue W, Bose S (2006) Calcium phosphatebased resorbable ceramics: influence of $\mathrm{MgO}, \mathrm{ZnO}$, and $\mathrm{SiO}_{2}$ dopants. J Am Ceram Soc 89: 2675-2688.

29. Dorozhkin SV, Epple M (2002) Biological and medical significance of calcium phosphates. Angew Chem Int Ed Engl 41: 3130-3146.

30. Best SM, Porter AE, Thian ES, Huang J (2008) Bioceramics: Past, present and for the future. J Eur Ceram Soc 28: 1319-1327.

31. Joschek S, Nies B, Krotz R, Göferich A (2000) Chemical and physicochemical characterization of porous hydroxyapatite ceramics made of natural bone. Biomaterials 21:1645-1658.

32. Daculsi G, LeGeros RZ, Nery E, Lynch K, Kerebel B (1989) Transformation of biphasic calcium phosphate ceramics in vivo: ultrastructural and physicochemical characterization. J Biomed Mater Res 23: 883-894.

33. de Bruijn JD, Klein CP, de Groot K, van Blitterswijk CA (1992) The ultrastructure of the bone-hydroxyapatite interface in vitro. J Biomed Mater Res 26: 13651382.

34. Rey C (1990) Calcium phosphate biomaterials and bone mineral. Differences in composition, structures and properties. Biomaterials 11: 13-15.

35. Porter AE, Patel N, Skepper JN, Best SM, Bonfield W (2004) Effect of sintered silicate-substituted hydroxyapatite on remodelling processes at the boneimplant interface. Biomaterials 25: 3303-3314.

36. Yamaguchi M (2010) Role of nutritional zinc in the prevention of osteoporosis Mol Cell Biochem 338: 241-254

37. Liebmann-vinson A, Chaney BN (2005) Methods of surface modification to enhance cell adhesion. 
Citation: Chettri B, Nandi SK, Chanda A, Begam H (2012) Bone Ingrowth to Insulin like Growth Factor-1 Loaded Zinc Doped Hydroxyapatite Implants: an In Vivo Study. 1: 234. doi:10.4172/scientificreports.234

38. Boontheekul T, Mooney DJ (2003) Protein-based signaling systems in tissue engineering. Curr Opin Biotechnol 14: 559-565.

39. Kempen DH, Creemers LB, Alblas J, Lu L, Verbout AJ, et al. (2010) Growth factor interactions in bone regeneration. Tissue Eng Part B Rev 16: 551-566.

40. Kofron MD, Laurencin CT (2006) Bone tissue engineering by gene delivery. Adv Drug Deliv Rev 58: 555-576.

41. Shimaoka H, Dohi Y, Ohgushi H, Ikeuchi M, Okamoto M, et al. (2003) Recombinant growth/differentiation factor-5 (GDF-5) stimulates osteogenic differentiation of marrow mesenchymal stem cells in porous hydroxyapatite ceramic. J Biomed Mater Res A 68: 168-176.

42. Kelpke SS, Zinn KR, Rue LW, Thompson JA (2004) Site-specific delivery of acidic fibroblast growth factor stimulates angiogenic and osteogenic responses in vivo. J Biomed Mater Res A 71: 316-325.

43. Damien E, Hing K, Saeed S, Revell PA (2003) A preliminary study on the enhancement of the osteointegration of a novel synthetic hydroxyapatite scaffold in vivo. J Biomed Mater Res A 66A: 241-246.

44. Damien E, Price JS, Lanyon LE (1998) The estrogen receptor's involvement in osteoblasts' adaptive response to mechanical strain. J Bone Miner Res 13: $1275-1282$.

45. Arinzeh TL, Peter SJ, Archambault MP, van den Bos C, Gordon S, et al. (2003) Allogeneic mesenchymal stem cells regenerate bone in a critical-sized canine segmental defect. J Bone Joint Surg Am 85-A: 1927-1935.

46. Nandi SK, Ghosh SK, Kundu B, De DK, et al. (2008) Evaluation of new porous $\beta$-tri-calcium phosphate ceramic as bone substitute in goat model. Small Ruminant Research 75: 144-153.

47. Nandi SK, Kundu B, Ghosh SK, De DK, Basu D (2008) Efficacy of nanohydroxyapatite prepared by an aqueous solution combustion technique in healing bone defects of goat. J Vet Sci 9: 183-191.
48. Yang X, Gan Y, Gao X, Zhao L, Gao C, et al. (2010) Preparation and characterization of trace elements-multidoped injectable biomimetic materials for minimally invasive treatment of osteoporotic bone trauma. J Biomed Mater Res A 95: 1170-1181.

49. Perrien DS, Brown EC, Aronson J, Skinner RA, Montague DC, et al. (2002) Immunohistochemical study of osteopontin expression during distraction osteogenesis in the rat. J Histochem Cytochem 50: 567-574.

50. Ramay HR, Zhang M (2004) Biphasic calcium phosphate nanocomposite porous scaffolds for load-bearing bone tissue engineering. Biomaterials 25 : 5171-5180.

51. Bose S, Suguira S, Bandyopadhyay A (1999) Processing of controlled porosity ceramic structures via fused deposition. Scripta Materialia 41: 1009-1014.

52. Yang S, Leong KF, Du Z, Chua CK (2001) The design of scaffolds for use in tissue engineering. Part I. Traditional factors. Tissue Eng 7: 679-689.

53. Damien E, Price JS, Lanyon LE (2000) Mechanical strain stimulates osteoblast proliferation through the estrogen receptor in males as well as females. J Bone Miner Res 15: 2169-2177.

54. Hock JM, Centrella M, Canalis E (1988) Insulin-like growth factor I has independent effects on bone matrix formation and cell replication. Endocrinology 122: $254-260$.

55. Gibson CJ, Thornton VF, Brown WA (1978) Incorporation of tetracycline into impeded and unimpeded mandibular incisors of the mouse. Calcif Tissue Res 26: 29-31.

56. Dahners LE, Bos GD (2002) Fluorescent tetracycline labeling as an aid to debridement of necrotic bone in the treatment of chronic osteomyelitis. J Orthop Trauma 16: 345-346.

57. Nandi SK, Kundu B, Datta S, De DK, Basu D (2009) The repair of segmental bone defects with porous bioglass: An experimental study in goat. Res Vet Sci 86: $162-173$ 